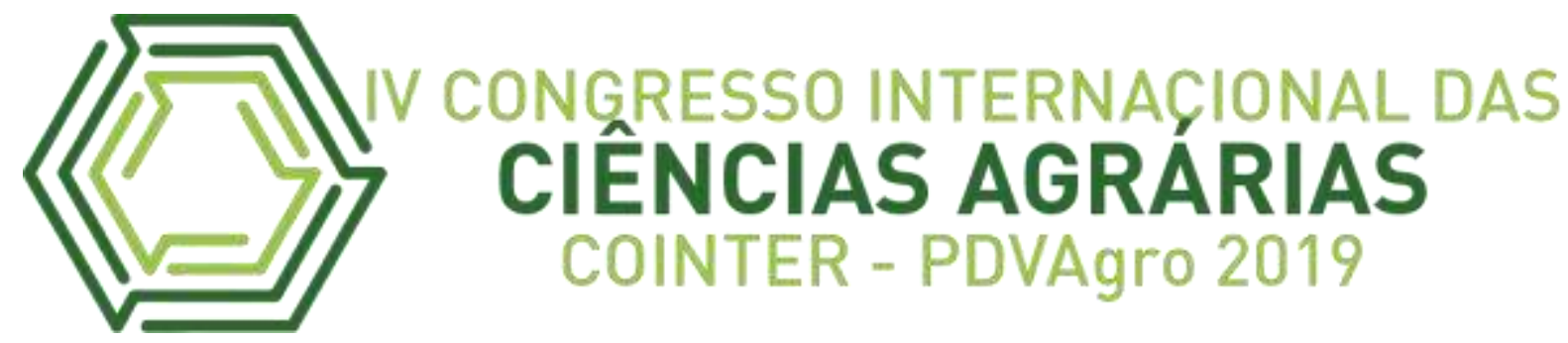

\title{
PERSPECTIVAS DE PRODUÇÃO DA MANDIOCA NO MUNICÍPIO DE TOMÉ- AÇU/PA
}

\author{
PERSPECTIVAS PARA LA PRODUCCIÓN DE YUCA EN EL MUNICIPIO DE \\ TOMÉ-AÇU / PA
}

\section{PERSPECTIVES FOR THE PRODUCTION OF CASSAVA IN THE MUNICIPALITY OF TOMÉ-AÇU / PA}

\author{
Apresentação: Comunicação Oral \\ Myrella Katlhen da Cunha de Araujoㅜ; Ramon Rene de Cristo Silva²; Omar Silva Souza; \\ Everaldo Lucas Moraes ${ }^{4}$; Márcia Alessandra Brito de Aviz ${ }^{5}$
}

DOI: https://doi.org/10.31692/2526-7701.IVCOINTERPDVAgro.2019.0011

\begin{abstract}
Resumo
A produção de mandioca tem se demonstrado expressiva ao longo dos anos na região norte brasileira, com a segunda maior área plantada e a maior produção de mandioca do Brasil. Logo, o intuito da pesquisa é verificar quais aspectos atribuem a produção de mandioca na região e verificar a capacidade de melhores condições de produção no município de ToméAçu/PA. Dessa forma, o presente estudo foi realizado no município de Tomé- Açu/PA, a partir da revisão literária atribuída a especificidades gerais da Cultura, Produtos e subprodutos, Aspectos botânicos e agronômicos, Manejo de adubação, Tratos fitossanitários, Manejo de pragas e doenças e a Cadeia de comercialização da mandioca, considerando as condições edafoclimáticas ofertadas pelo local e as requeridas pela cultura. Como resultado, foi observada a importância da espécie para a produção agroindustrial nos produtos e subprodutos, principalmente para a utilização das raízes. Bem como, questões culturais das regiões produtoras, como é observado para a produção de farinha local. Com isso, para obtenção do produto o processo de produção foi baseado em: arranquio, transporte, o descascamento, ralação, prensagem para o tucupi, a busca da lenha, a torrefação, a tintura e o ensacamento. Ainda, no município de Tomé-Açu verifica-se que a cultura apresenta potencial produção considerando sua rusticidade, resistência e ampla adaptabilidade em regiões tropicais e subtropicais, no entanto, é necessário o investimento em pesquisas que facilitem o manejo de pragas e doenças e elevem o rendimento do material produzido. Ademais, considerando que a espécie é produzida predominantemente por pequenos agricultores, é
\end{abstract}

\footnotetext{
${ }^{1}$ Engenharia Agrícola, Universidade Federal Rural da Amazônia - UFRA, myrellakaraujo@gmail.com

${ }^{2}$ Engenharia Agrícola, Universidade Federal Rural da Amazônia - UFRA, reneramon42@gmail.com

${ }^{3}$ Engenharia Agrícola, Universidade Federal Rural da Amazônia - UFRA, omarsilvasouza@gmail.com

${ }^{4}$ Engenharia Agrícola, Universidade Federal Rural da Amazônia - UFRA, luccasmoraes.Im@gmail.com

${ }^{5}$ Doutorado em Ciências Agrárias, Universidade Federal Rural da Amazônia - UFRA, marciaaviz@yahoo.com.br
} 
necessário o incentivo governamental na atividade, adaptação dos agricultores a práticas conservacionistas dos recursos naturais e o manejo adequado da cultura para melhores condições de produção e conseqüente aumento da produtividade das lavouras na região.

Palavras-Chave: mandioca, Tomé-Açu, indústria da mandioca.

\section{Resumen}

La producción de yuca ha sido expresiva a lo largo de los años en la región norte de Brasil, con la segunda mayor área plantada y la mayor producción de yuca en Brasil. Por lo tanto, el propósito de la investigación es verificar qué aspectos atribuyen la producción de yuca en la región y verificar la capacidad de mejores condiciones de producción en el municipio de Tomé-Açu/PA. Por lo tanto, el presente estudio se realizó en el municipio de Tomé-Açu/PA, basado en la revisión literaria atribuida a las especificidades generales de Cultura, Productos y subproductos, Aspectos botánicos y agronómicos, Manejo de la fertilización, Tratamientos fitosanitarios, Manejo de plagas y enfermedades. y la cadena de comercialización de yuca, considerando las condiciones edafoclimáticas que ofrece el local y las requeridas por el cultivo. Como resultado, se observó la importancia de las especies para la producción agroindustrial en productos y subproductos, especialmente para el uso de raíces. Además de los problemas culturales de las regiones productoras, como se observa para la producción local de harina. Por lo tanto, para obtener el producto, el proceso de producción se basó en: desgarro, transporte, pelado, rallado, prensado de tucupi, búsqueda de leña, tostado, teñido y embolsado. Aún así, en el municipio de Tomé-Açu se verifica que el cultivo tiene una producción potencial considerando su rusticidad, resistencia y amplia adaptabilidad en regiones tropicales y subtropicales, sin embargo, es necesario invertir en investigación que facilite el manejo de plagas y enfermedades y elevar el rendimiento del material producido. Además, teniendo en cuenta que la especie es producida predominantemente por pequeños agricultores, es necesario alentar al gobierno en la actividad, adaptar a los agricultores a las prácticas conservacionistas de los recursos naturales y el manejo apropiado del cultivo para mejores condiciones de producción y el consiguiente aumento de la productividad del cultivo en la región.

Palabras Clave: yuca, Tomé-Açu, industria de la yuca.

\footnotetext{
Abstract

Cassava production has been expressive over the years in the northern Brazilian region, with the second largest planted area and the largest cassava production in Brazil. Therefore, the purpose of the research is to verify which aspects attribute cassava production in the region and to verify the capacity of better production conditions in the municipality of Tomé-Açu / PA. Thus, the present study was conducted in the municipality of Tomé-Açu / PA, based on the literary review attributed to general specificities of Culture, Products and Byproducts, Botanical and Agronomic Aspects, Fertilization Management, Phytosanitary Treatments, Pest and Disease Management. and the cassava commercialization chain, considering the edaphoclimatic conditions offered by the local and those required by the crop. As a result, it was observed the importance of the species for agroindustrial production in products and byproducts, especially for the use of roots. As well as cultural issues of producing regions, as
} 
is observed for local flour production. Thus, to obtain the product, the production process was based on: tearing, transportation, stripping, grating, pressing for tucupi, searching for firewood, roasting, dyeing and bagging. Still, in the municipality of Tomé-Açu it is verified that the crop has potential production considering its rusticity, resistance and wide adaptability in tropical and subtropical regions, however, it is necessary to invest in research that facilitate the management of pests and diseases and raise the yield of the material produced. Moreover, considering that the species is predominantly produced by small farmers, it is necessary to encourage the government in the activity, adapt farmers to conservationist practices of natural resources and the appropriate management of the crop for better production conditions and consequent increase of crop productivity in the region.

Keywords: cassava, Tomé-Açu, cassava industry.

\section{Introdução}

O plantio de mandioca tem ritmo estável nas áreas plantadas no território brasileiro, com exceção da região norte, com acréscimo de quase $20 \%$ em extensão territorial, com a segunda maior área e maior produção de mandioca com $20,55 \%$ da produção nacional. Já o nordeste obteve reduções de mais de $20 \%$, porém se destaca em áreas de plantio (FERNANDES et al., 2018).

Em 2015 o Brasil conseguiu exportar cerca de 35 mil toneladas de fécula. O uso de fécula de mandioca gera produtos dos mais variados em meio as exportações do produto e nos diversos ramos industriais como de papeis, frigoríficos, indústria química e a têxtil (SEAB, 2016).

Ainda, existem dois grupos de mandioca, tanto para a Manihot utilissima (macaxeira ou aipim ou ainda mandioca doce) quanto para a Manihot esculenta (mandioca brava ou mandioca amarga). Atendendo a possibilidade de produção de derivados na modalidade de pré-prontos, novas perspectivas de mercado e praticidade ao consumidor, outras formas de aproveitamento da planta além da raiz, são a utilização dos caules e folhas como alimentação animal, suprindo a necessidade nutricional e rentável aos produtores (HUE et al., 2010). Contudo, a maior produtividade de mandioca é destinada à indústria de farinha e derivados (CARDOSO et al., 2004).

Com isso, a produção da região norte tem demonstrado potencial na produção de mandioca. Logo, o intuito da presente pesquisa é verificar os aspectos da cadeia produtiva da mandioca a qual tem atribuído resultados positivos na região norte brasileira.

\section{Fundamentação Teórica}


A mandioca (Manihot esculenta Crantz) é uma espécie de origem sul americana, pertencente à família das euforbiáceas. Inicialmente cultivada por indígenas, apresenta maior interesse na obtenção de suas raízes, para produção da fécula e a raspa, útil para a alimentação e para fins da indústria (CASTRO e MOREIRA, 2016).

Conforme o teor de linamarina, substância passível a transformação em ácido cianídrico no estomago animal ou humano. Em vista disso, designa sua classificação em mandioca mansa e mandioca brava, respectivamente de mesa e industrial (CASTRO e MOREIRA, 2016). Componente importante da alimentação brasileira e matéria prima da indústria do amido, a qual pode ser cultivada em todo o Brasil. O resíduo (bagaço) produzido da extração da composição fécula e parte fibrosa do produto, rico em carboidratos e fibras, com pequena presença de lipídios e proteínas (MATSUI et al., 2003).

Das raízes pode ser feita a farinha de mesa, beijus, tapioca e puba ou carimã. Além disso, poder ser consumida frita, cozida, em sopas, bolinhos, angu, mingau, bolo e broa. $\mathrm{O}$ caule utilizado para a forragem animal, e com as folhas, forragem e alimentação humana (CASTRO e MOREIRA, 2016).

Ainda, de acordo com IBGE (2019) o cultivo de mandioca representou área plantada 1.537.282 ha de área plantada e área colhida de 1.338.328 ha como descreve as figuras 1 e 2 .

Figura 1: Gráfico da distribuição de área plantada nas grandes regiões brasileiras.

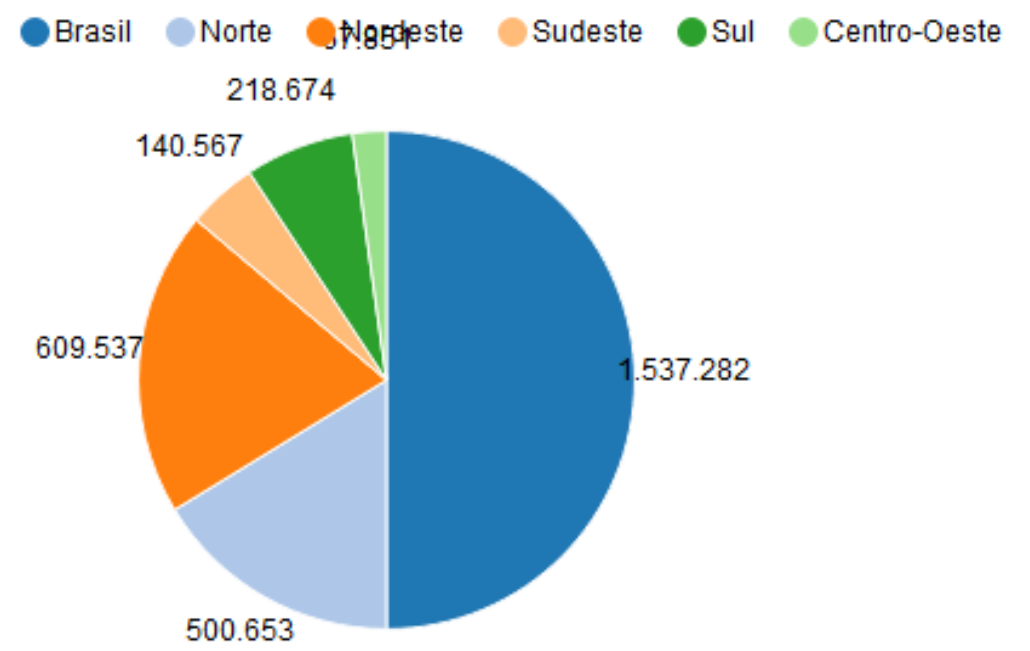

Fonte: IBGE - Levantamento Sistemático da Produção Agrícola

Apesar dos valores expressivos, no ano de 2018 a área plantada de mandioca foi de (2.149.409 ha), com área colhida de (1.415.912 ha) superiores ao que foi obtido até o mês de julho de 2019. 
Figura 2: Gráfico da distribuição de área colhida nas grandes regiões brasileiras.

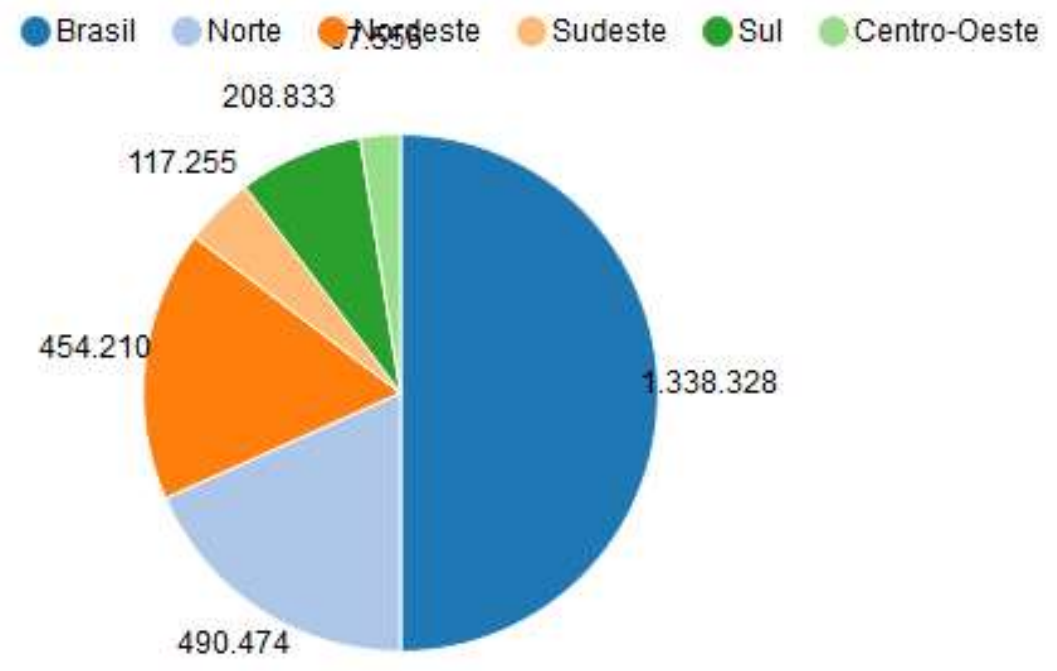

Fonte: IBGE - Levantamento Sistemático da Produção Agrícola

Embora a área plantada da região nordeste com (609.537 ha) seja superior a região norte (500.653 ha), observa-se que a região norte se destacou em relação a área colhida ao colher (490.474 ha) de mandioca. Dessa maneira, pela expressiva produção na região norte é necessário conhecer melhores aspectos de produção da cultura, elevando a produtividade da mandioca no município de Tomé-Açu/PA.

\section{Metodologia}

O presente estudo foi realizado no município de Tomé- Açu/PA com coordenadas geográficas $\left(01^{\circ} 24^{\prime} 46,14\right.$ " e $01^{\circ} 28^{\prime} 4,11^{\prime \prime}$ de latitude sul) e $\left(48^{\circ} 20^{\prime} 4,60^{\prime \prime}\right.$ e $48^{\circ} 20^{\prime} 31,84^{\prime \prime}$ de longitude), $45 \mathrm{~m}$ de altitude (VALENTE et al., 2014). A fim de conhecer aspectos da cultura da mandioca.

Segundo a classificação de Köppen o tipo climático é Ami, com média pluviométrica de $2.300 \mathrm{~mm}$, fotoperíodo de 2.300 horas, temperatura média de $26,4^{\circ} \mathrm{C}$ anual e umidade relativa do ar média de $85 \%$ (PACHÊCO et al., 2009).

O estudo de caráter qualitativa foi desenvolvido no município de Tomé-Açu/PA a partir da revisão literária atribuída a especificidades gerais da Cultura no norte brasileiro, Produtos e subprodutos, Aspectos botânicos e agronômicos, Manejo de adubação, Tratos fitossanitários, Manejo de pragas e doenças e a Cadeia de comercialização para verificar os princípios que regem os resultados positivos da produção paraense e verificar possíveis melhorias na produção Tomeaçuense. 
Ademais, foi realizada a análise descritiva dos dados obtidos a partir da literatura de Berwanger (2018); Modesto Júnior e Alves (2016) e Gomes e Leal (2003) na região norte e senso agrícola recente entre os anos de (2017-2019).

\section{Resultados e Discussão}

De acordo com Modesto Júnior e Alves (2016) o estado do Pará é o maior produtor de mandioca e as atividades prestadas na região na produção da mandioca são: arranquio, transporte, o descascamento, ralação, prensagem para o tucupi, a busca da lenha, a torrefação, a tintura, o ensacamento. Muito presente na alimentação da população Amazônica, em destaque de baixa renda e pouco incentivada. Porém ainda conta com o crédito do Fundo Constitucional de Financiamento do Norte (FNO) destinado a atividade de pequenos agricultores.

Figura 3: Produção das lavouras de mandioca no Brasil.

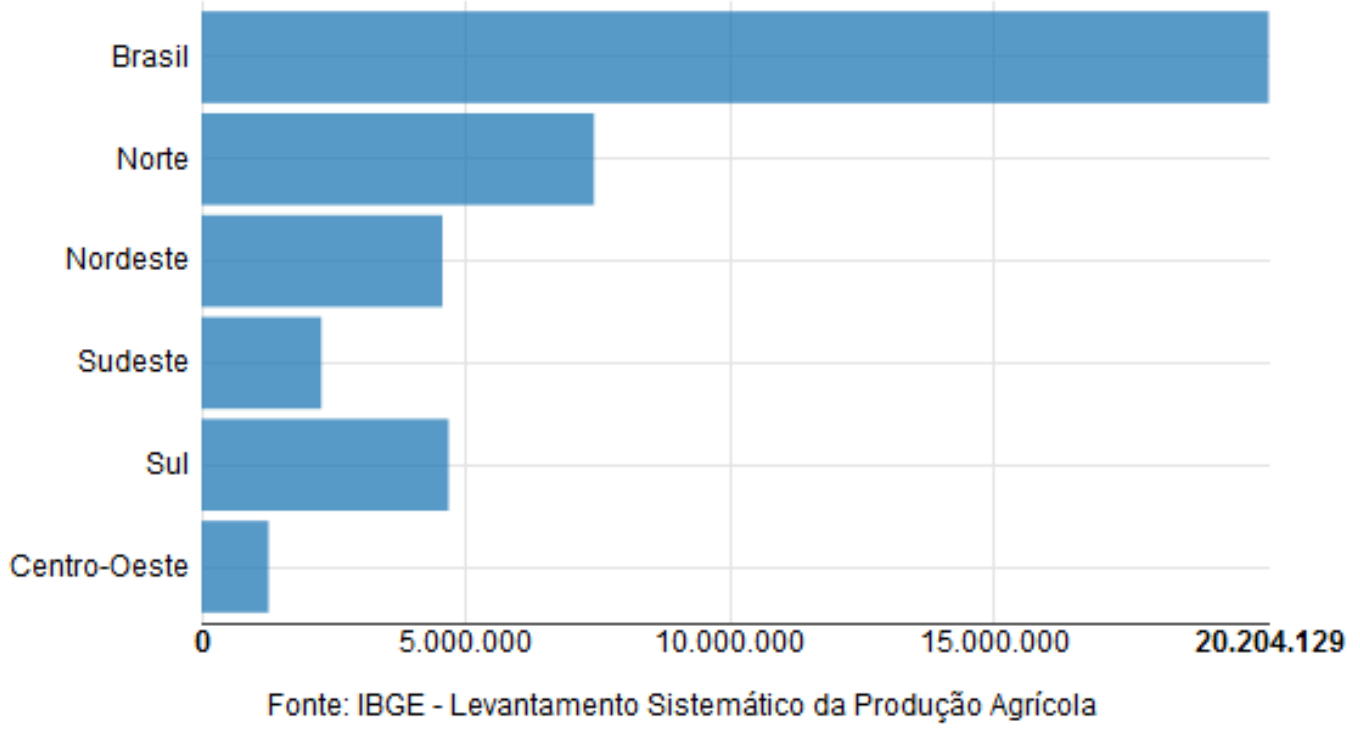

Com o cultivo da mandioca no Pará é evidente a prática de derruba e queima, devido as maiores produtividades advindas de mesorregiões com maior biomassa em capoeiras ou florestas e de expansão da fronteira agrícola (MODESTO JÚNIOR e ALVES, 2016).

Nessa perspectiva os aspectos levantados na pesquisa buscam melhorar as condições de plantios já existentes em Tomé-Açu e fomentar literatura para incentivar a produção de maniva na região.

\section{Produtos e subprodutos}

Os produtos e os subprodutos demonstram elevados teores de carboidratos nãoestruturais, com destaque ao amido (GAMA et al., 2015). A mandioca (Manihot esculenta, 
Crantz, Manihot utilíssima e Manihot ahipi), aipim e macaxeira. Dos principais derivados, a farinha é uma das mais importantes, submetida a diferentes processos tecnológicos de fabricação e beneficiamento; a fécula, extraída das raízes de mandioca, não fermentada, adquirida por decantação, centrifugação ou processos tecnológicos; e a tapioca, que pode ter forma de grânulos irregulares, poliédricos ou esféricos dependendo do processo submetido (SANTOS et al., 2018).

\section{Aspectos botânicos}

Conforme Guimarães et al. (2017) existem poucos estudos a respeito dos aspectos botânicos das diversas variedades de mandioca. Com isso, ressalta a necessidade de conhecer a morfologia das plantas, frente a suas particularidades e adaptabilidade a diferentes regiões.

Porém, de acordo com estudo de Siviero e Schott (2011) demonstrou que das cultivares estudadas, $(98,06 \%)$ apresentaram cor das folhas em tom verde e uma folha com cor roxa $(1,94 \%)$. O comprimento do pecíolo variou entre 6,46 a 22,26 $\mathrm{cm}$. Na parte aérea as características foram identificadas: sinuosidade do lóbulo foliar (liso,87,37\%); morfologia do lóbulo (ovalada, 75,73\%); hábito de crescimento (dicotômico, $75,73 \%$ ) e cor externa do caule (marrom, 88,35\%). A altura das plantas foi de 1,32 a 3,61m, com florescimento entre 125 a 226 dias. Em relação a raiz, $(95,14 \%)$ possuía pedúnculo; $(43,69 \%)$ forma cônica cilíndrica;(66\%) cor externa marrom escuro;(44,66\%) possuem córtex de cor creme;(46,60\%) possuem cor da polpa branca;(91,26\%)textura da epiderme rugosa; (54,38\%) médias constrições; $(93,20 \%)$ fácil destaque da película e $(85,43 \%)$ fácil destaque do córtex.

\section{Aspectos agronômicos}

A espécie possui grande adaptabilidade, visto que se desenvolve em regiões tropicais e subtropicais, resistente a seca, no entanto, pouco adepta a temperaturas inferiores a $15^{\circ} \mathrm{C}$. Quanto aos solos, é cultivável em vários tipos de solo, porém não se recomenda condições de alagamento ou solos muito arenosos (CASTRO e MOREIRA, 2016).

A área de plantio deve ser preparada inicialmente com aração e gradagem niveladora, para facilitar o desenvolvimento radicular (RÓS e SÃO JOÃO, 2016) e reitera que deve ser realizada a capina da área para controle de plantas invasoras. Para plantio da mandioca, são feitos sulcos de $1,20 \mathrm{~m}$ com 5 a $10 \mathrm{~cm}$ de profundidade, e depositadas as manivas de $(15 \mathrm{~cm}$ de comprimento) a cada $60 \mathrm{~cm}$ no sentido horizontal, posteriormente cobertas com solo (NORMANHA e PEREIRA, 1950). O espaçamento do plantio indicado no estudo de Lima et al. (2018) foi de 0,90 metros entre linhas. 
As manivas utilizadas para plantio são obtidas do terço médio, de hastes de plantas com dez meses de idade (RÓS e SÃO JOÃO, 2016). Cuja colheita no estudo de Rós e São João (2016) foi realizada aos 270 dias após o plantio, ao verificar se as raízes eram saudáveis e o comprimento e diâmetro iguais ou superiores a 10 e a $3 \mathrm{~cm}$, respectivamente.

\section{Manejo de adubação}

Os procedimentos de calagem e adubação devem ser realizados com 60 dias antes do plantio e conforme a necessidade nutricional apresentada pela análise de solo. A mandioca apresenta potencial conversão de nutriente, logo, em uma produção de 25 toneladas de raízes + parte aérea de mandioca/ha são extraídos $123 \mathrm{~kg}$ de N, 27kg de P, $146 \mathrm{~kg}$ de $\mathrm{K}, 46 \mathrm{~kg}$ de Ca e $20 \mathrm{~kg}$ de $\mathrm{Mg}$. Cuja ordem decrescente de absorção de nutrientes é: $\mathrm{K}>\mathrm{N}>\mathrm{Ca}>\mathrm{P}>\mathrm{Mg}$. A aplicação de calcário não tem demonstrado diferença significativa nos cultivos de mandioca, visto que a cultura possui característica tolerante a acidez.

Porém, após o cultivo sequencial em uma mesma área as plantas podem começar a responder a aplicação de calcário, até mesmo como suprimento de cálcio e magnésio, terceiro e quinto nutrientes mais absorvidos. O nitrogênio também tem apresentado pequenas respostas, até em solos com pouca matéria orgânica.Com isso, apresenta significante resposta a adubação fosfatada, embora não consiga extraí-lo do solo em grandes quantidades em consequência de sua escassez nos solos brasileiros. Entre os elementos, o nutriente mais extraído é o potássio, no qual após 2 a 4 cultivos sucessivos na mesma área é esgotado. Assim, a tabela 1 apresenta as recomendações de adubos para a mandioca (MATTOS e BEZERRA, 2003).

Tabela 1: Recomendação de adubação para a cultura da mandioca.

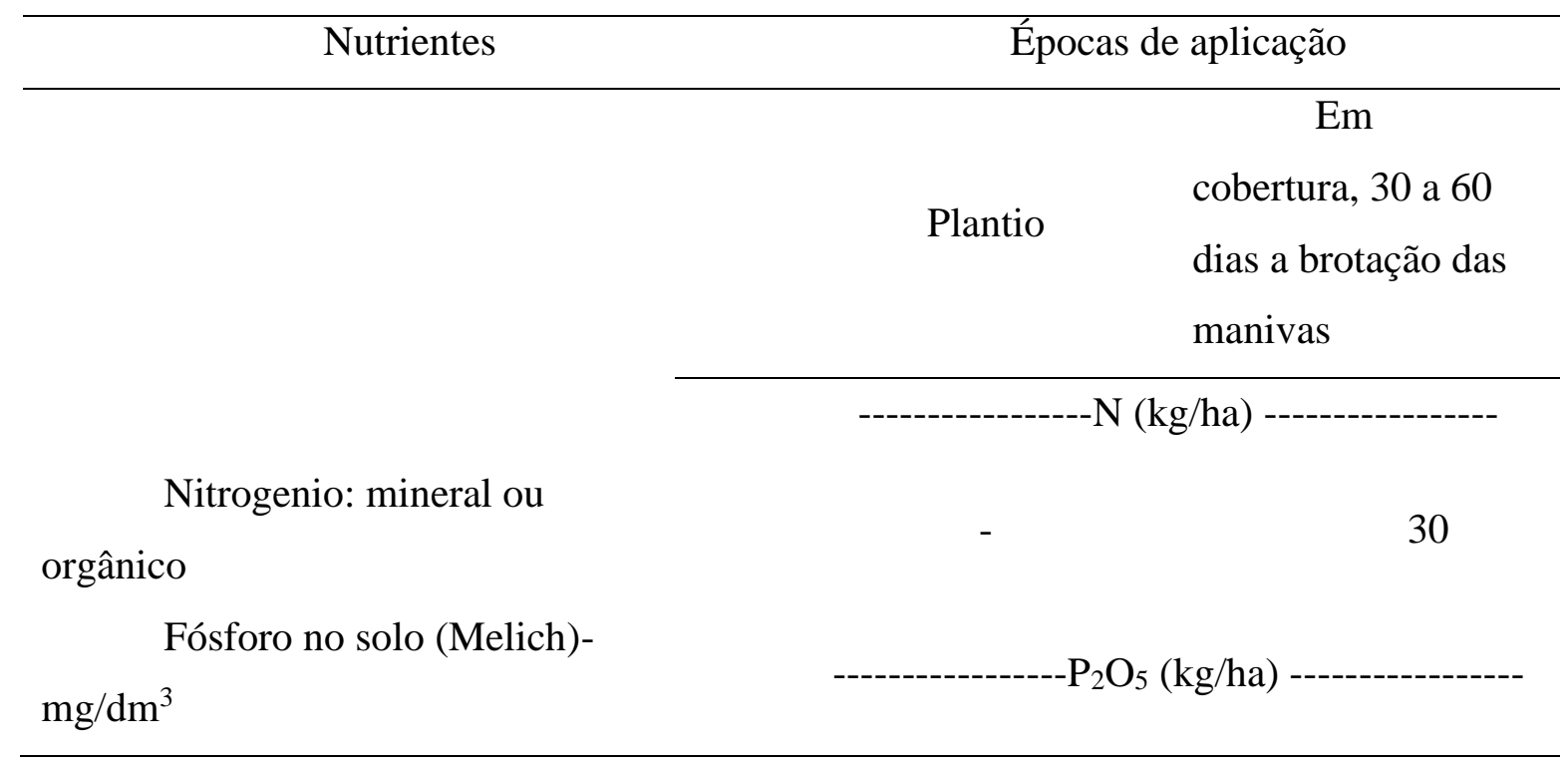




\begin{tabular}{cccc}
\hline & Até 3 & 60 & - \\
4 a 6 & 40 & - \\
7 a 10 & 20 & \\
\multicolumn{2}{c}{ Potássio no solo (Melich) - } & & - \\
$\mathrm{mg} / \mathrm{dm}^{3}$ & Até 20 & 40 & - \\
& 21 a 40 & 30 & - \\
\hline
\end{tabular}

Fonte: Mattos e Bezerra (2003).

Com os procedimentos realizados em doses, épocas e modos de aplicação adequada é esperado o rendimento médio de 20 toneladas de raízes por hectare (MATTOS e BEZERRA, 2003). Apesar disso, por ser considerada uma cultura rústica e muito cultivada por pequenos agricultores, são realizadas poucas práticas de manejo e utilizados poucos insumos. Dessa maneira, dispondo de baixo rendimento (ALVES FILHO et al., 2015).

\section{Tratos fitossanitários}

No tocante aos tratos da cultura, é evidente a prática de controle as ervas daninhas. Todavia, são realizados poucos cuidados, que deixam a desejar quanto ao ataque de invasores não tão visíveis como pragas, doenças e deficiências minerais. Esse problema justifica-se a fácil e barata retirada do mato, mas prejudica o aumento da produção e qualidade dos produtos (MATTOS e BEZERRA, 2003).

\section{Manejo de pragas e doenças}

As pragas e doenças foram descritas suas características em função do plantio e importância, ataque e práticas de controle, segundo as literaturas de Gomes e Leal (2003) e Lima (2017).

\section{Pragas}

Mandarová: É uma lagarta e considerada uma praga importante pela distribuição geográfica e elevada capacidade de consumo foliar. Pode causar desfolhamento severo, que nos primeiros meses da cultura pode reduzir o rendimento e ocasionar a morte de plantas jovens. Sua incidência pode ocorrer em qualquer época do ano, mas evidenciada durante o início da estação chuvosa ou da seca, e esporádica. 
É ideal que seja realizada a aração em novos plantios para enterrio profundo das pupas e as superficiais expostas ao sol e inimigos naturais. Também, eliminar plantas invasoras que possam ser hospedeiras das pragas. Além da rotação de culturas, em condições de ataque frequente, como também, inspeções do plantio e identificação de focos.

Em cultivos pequenos pode ser feita a catação manual e destruição das lagartas. Mas recomenda-se o uso de inseticida biológico seletivo à base de Bacillus thuringiensis quando aplicado em lagartas com $5 \mathrm{~mm}$ e 3,5 cm de comprimento, em o primeiro e terceiro ínstares. Outro agente biológico é o Baculovirus erinnyis, vírus que ataca as lagartas. Útil quando encontradas de cinco a sete lagartas pequenas por planta, esse controle é decorrente da maceração de lagartas infectadas na lavoura. Visto isso, é recomendado o uso de inimigos naturais e armadilhas luminosas para captura dos adultos, pois o controle químico destrói os insetos benéficos.

Ácaros: pragas severas, encontrados na face inferior das folhas durante a estação seca do ano e podem causar danos consideráveis, encontradas no Nordeste e Centro-Oeste brasileiro. A praga penetra o estilete no tecido foliar e succionam o conteúdo celular. Os sintomas são: manchas cloróticas, pontuações e bronzeamento no limbo, morte das gemas, deformações e queda das folhas, reduzindo a área foliar e a fotossíntese. Podem causar redução foliar, induzir novas ramificações, as hastes tornam-se ásperas e de cor marrom e o desfolhamento e morte das hastes.

No entanto, temperaturas baixas ou mudanças bruscas reduzem as populações. A umidade relativa alta e contínua, afeta a oviposição, eclosão e sobrevivência das formas imaturas e aparecimento de inimigos naturais. Além da chuva forte que elimina por afogamento ou golpe direto das gotas de água. Recomenda-se para o controle cultivares resistentes e/ou tolerantes. Outrossim, existem inimigos naturais como: coleópteros e ácaros benéficos da família Phytoseiidae e o fungo Neozygites sp.

Percevejo de renda: Tem hábito sugador e ocorre durante épocas secas, são encontrados na face inferior das folhas medianas e basais da planta; em casos severos chegando às folhas apicais. $\mathrm{O}$ controle é por cultivares mais tolerantes ao ataque. Essa praga pode ser controlada quimicamente, mas o ataque pode repetir-se rapidamente, e o uso contínuo de inseticidas é dispendioso, além de destruir os insetos benéficos.

Mosca-branca: Praga de alimentação direta e vetora de vírus, causar danos em mandiocas nos agroecossistemas. Os adultos são encontrados na face inferior das folhas da 
parte apical, e as ninfas na face inferior das folhas mais velhas. Pode causar reduções no rendimento das raízes, amarelecimento e encrespamento das folhas apicais e pequenos pontos cloróticos. Ainda, o dano indireto com a mela pelo agricultor, consiste na presença de um fungo conhecido como fumagina, que reduz a capacidade fotossintética da planta. O controle é por cultivares mais tolerantes.

Brocas do caule: As larvas são encontradas no interior das hastes, observada pela presença de excrementos e serragem que saem das galerias do inseto. As plantas podem perder folhas e secar. Recomenda-se remover e queimar as partes ou plantas infestadas, mandiocas sadias para plantio e cultivares não infectadas.

Cupins: Atacam a cultura durante períodos prolongados de estiagem. Nas plantas jovens, constroem galerias ocasionando o secamento da planta. Recomenda-se manter o ambiente limpo, proteger as plantas a fim de plantio, incorporar um inseticida ao solo, abaixo das manivas, no sulco ou cova, por ocasião do plantio.

Formigas cortadeiras: Podem desfolhar as plantas, com ataque durante os primeiros meses de desenvolvimento da maniva. O controle é por fumigação, em épocas chuvosas; com uso de isca granulada colocadas nos caminhos das formigas, em época seca e inseticidas líquidos em épocas chuvosas (GOMES e LEAL, 2003).

\section{Doenças}

De acordo com Lima (2017) no estado do Pará os patógenos associados à podridão mole radicular foram: oomicetos dos gêneros Phytophthora e Pythium, o fungo Fusarium solani e recentemente oomicetos do gênero Phytopythium. Doença comumente encontrada em cultivos cuja área apresente solo compactado e má drenagem. Grande responsável por imitações no desenvolvimento da mandioca e pelas perdas na produtividade, evidente em cultivos sem manejo adequado e culturas susceptíveis. Os sintomas são distintos devido aos inúmeros agentes causadores, no entanto em geral causa podridões moles nas raízes, odores fortes e coloração acinzentada (GOMES e LEAL, 2003).

O combate é feito através do uso de variedades resistentes, rotação de culturas, manejo físico do solo, o uso de microrganismos antagônicos, plantio em áreas bem drenadas, matéria vegetal livre de doenças e destruição do proveniente de áreas infestadas (GOMES e LEAL, 2003).

Bacteriose: Causada por Xanthomona scampestris pv. manihotis, é caracterizada por manchas angulares, aparência aquosa nos folíolos, murcha das folhas e pecíolos, morte 
descendente e exsudação de goma nas hastes, necrose dos feixes vasculares e morte da planta. As condições climáticas podem influenciar no aparecimento e severidade da doença, suscetibilidade ou tolerância das variedades, práticas culturais empregadas, épocas de plantio e nível de contaminação do material de plantio. Logo, podem ser utilizadas variedades resistentes, uso de material vegetal não afetado e época adequada para plantio.

Superalongamento: Causado por Sphaceloma manihoticola, é causada por fungos importantes. No Brasil foi observada em 1977, na Região Norte, no Amazonas e Pará. Os sintomas são: alongamento exagerado das hastes tenras ou em desenvolvimento, formando ramas finas com longos entrenós, lesões verrugoses nas hastes, pecíolos e nervuras, retorcimento das folhas, desfolhamento e morte dos tecidos. A disseminação ocorre por esporos e rápida durante a estação chuvosa, e até mesmo manivas-semente contaminadas. $\mathrm{O}$ controle é por uso de plantas sadias no plantio, retirada das afetadas, uso de cultivares tolerantes ou resistentes e rotação de culturas em áreas já afetadas.

Superbrotamento: causado por fitoplasma, a doença tem grande capacidade de se expandir e pode causar perdas na produção de manivas-semente, nas plantas afetadas, reduzo tamanho das hastes, eleva a brotação de gemas, provoca raquitismo e amarelecimento generalizado. Acredita-se que a disseminação seja por insetos sugadores e material contaminado. O controle pode ser seleção do material e eliminação de plantas doentes dentro do cultivo.

Viroses: O mosaico das nervuras apresenta ampla abrangência geográfica e os sintomas apresentam cloroses intensas entre as nervuras primárias e secundárias e retorcimento do limbo foliar. O "couro de sapo" tem sido observado em lavouras no Amazonas, Pará e Bahia. Pode reduzir a qualidade do produto, em função dos teores de amido nas raízes (10 a 80\%).

Outras doenças: a antracnose (Colletotrichum gloeosporioides) pode afetara cultura em determinadas épocas causando perdas na produção de raízes e qualidade dos produtos. As cercosporioses em mandioca não causam muitos prejuízos (GOMES e LEAL, 2003).

\section{Cadeia de comercialização}

Figura 4: Fluxograma da cadeia produtiva da mandioca. 


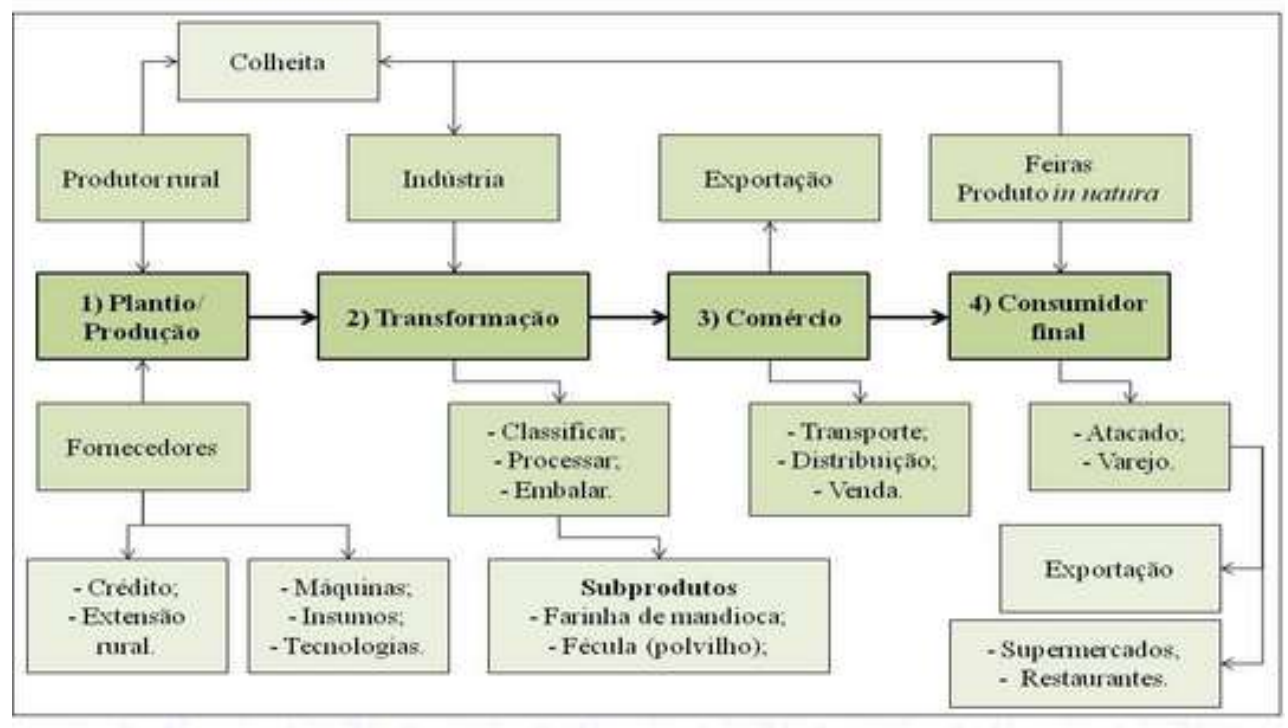

Fonte: Berwanger (2018)

A mandioca é comumente consumida in natura, por produtores ou por venda direta ao consumidor local, comercialização em feiras, supermercados, para atravessadores ou agroindústrias. Sua produção é maior a esse destino, como mandioca de mesa. O mercado da farinha é vasto dependente da região produtora, que nas regiões norte e nordeste pode ser comercializada localmente, no qual o produtor é responsável pela venda direta ao consumidor, principalmente em feiras livres. Outro caso é a produção ao comércio varejista local ou regional, que conta com atravessadores e atacadistas de exportação ou revenda.

A fécula pode ser utilizada na forma fermentada, modificada e in natura, conforme o destino no setor industrial. Dessa forma, é destinada para a venda direta a empresas para geração de novos produtos, como descreve a figura 5.

Figura 5: Uso da fécula de mandioca.

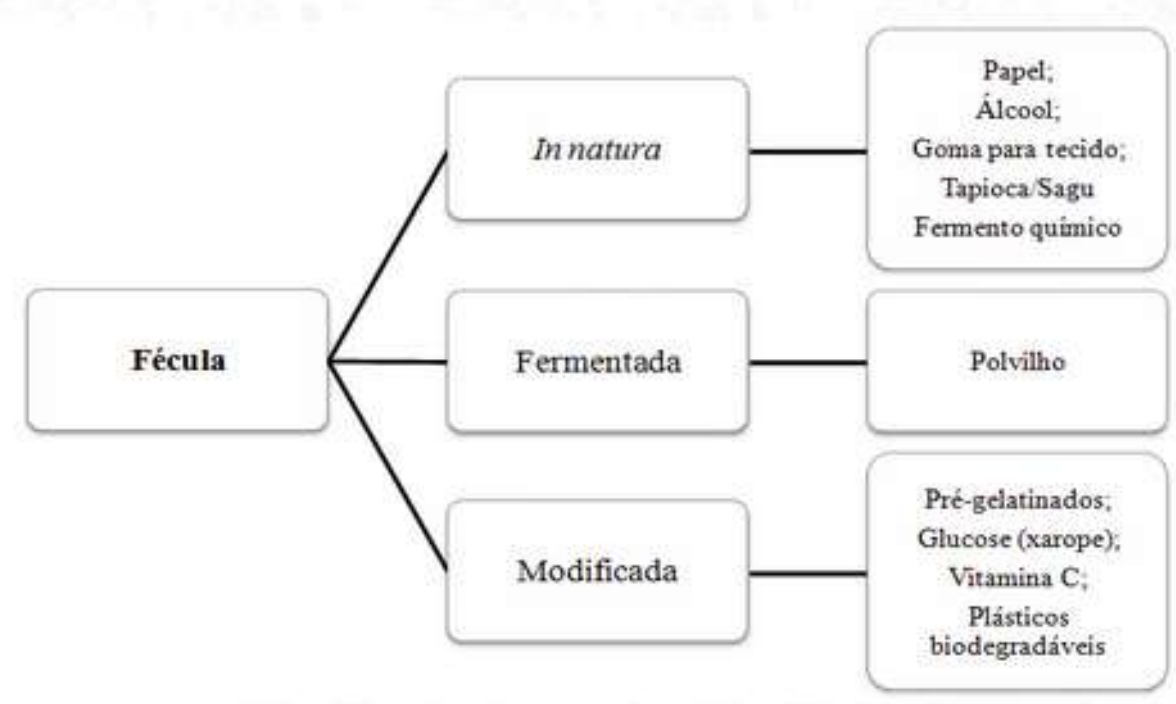


Fonte: Berwanger (2018)

O sistema produtivo da cadeia da mandioca apresenta três tipologias básicas: a unidade doméstica, familiar e a empresarial. Considerando a origem da mão-de-obra, nível tecnológico, participação no mercado e intensidade de capital na exploração. A unidade doméstica é caracterizada pela mão-de-obra familiar, ausência de tecnologias modernas, pouco participar do mercado e capital de exploração de baixa intensidade. A unidade familiar possui poucas tecnologias modernas, tem participação significativa no mercado e dispõe de capital de exploração considerável. Ainda, a contratação de mão-de-obra de terceiros é a característica marcante da unidade empresarial.

A escala de operação das indústrias de processamento de farinha vai de pequenas unidades artesanais de processamento, até unidades de grande porte. Na cadeia da mandioca existem ainda outros produtos de importância econômica regional, comercializados informalmente, a raspa de mandioca e da parte aérea (GOMES e LEAL, 2003).

\section{Conclusões}

Com a importância da espécie para a produção agroindustrial na produção de produtos e subprodutos, bem como, questões culturais das regiões produtoras, é necessário o investimento em pesquisas que facilitem o manejo de pragas e doenças e elevem o rendimento do material produzido. Ainda, considerando que a espécie é produzida predominantemente por pequenos agricultores no município de Tomé-Açu, é necessário o incentivo governamental, adaptação a práticas conservacionistas e manejo adequado para melhores condições de produção e aumento da produtividade da lavoura.

\section{Referências}

ALVES FILHO, P.P.C.; JESSIVALDO RODRIGUES GALVÃO, J.R.; NEVES, L.B.; COSTA, I.R. Resposta da Cultivar de Mandioca Roxinha à Adubação NPK. Revista Raízes e Amidos Tropicais, Botucatu, v. 11, n. 1, p. 1-7, 2015.

BERWANGER, A. Estudo sobre a Cadeia Produtiva da Mandioca. Revista ea. n. 63, 2018. CARDOSO, C. E. L.; SOUZA, J. S. Importâncias, potencialidade do cultivo da mandioca na América Latina. In: CEREDA, M. P. (Coord.). Culturas de tuberosas amiláceas latino americanas. v.2, p.29-48, 2019.

CASTRO, J.E.G.; MOREIRA, C.A.L. Aspectos Econômicos e sociais da Cadeia Produtiva da Mandioca no Brasil. Revista Científica FACPED, v.2, n.2, p.23-30, 2016. 
FERNANDES, G. (2018) Mandioca em números. Embrapa Amazônia Oriental. Disponível em:<https://www.embrapa.br/congresso-de-mandioca-2018/mandioca-em-numeros>. Acesso em: jul. 2019.

GAMA, T.S.S.; LUCAS, F.C.A.; LOBATO, G.J.M. Morfologia dos grãos de amido de cultivares de mandioca (Manihot esculenta Crantz) em Caxiuanã, Pará, Brasil. Scientia Amazonia, v. 4, n.3, 63-68, 2015.

GOMES, J.C.; LEAL, E.C. 2003. Cultivo da Mandioca para a Região dos Tabuleiros Costeiros.Embrapa Mandioca e Fruticultura. Sistemas de Produção 11. Disponível em: https://sistemasdeproducao.cnptia.embrapa.br/FontesHTML/Mandioca/mandioca_tabcosteiro s/doencas.htm>. Acesso: jul. 2019.

GUIMARÃES, D.G.; PRATES, C.J.N.; VIANA, A.E.S.; CARDOSO, A.D.; TEIXEIRA, P.R.G.; CARVALHO, K.D. Caracterização morfológica de genótipos de mandioca (Manihot esculenta Crantz). Scientia Plena, v.13, n.9, p.1-11, 2017.

HUE, K.T.; VAN, D.T.T.; LEDIN, E.U.; SPORNDLY, E.; WREDLE, E. Efeito da alimentação fresca, murcha e folhagem seca ao sol de mandioca (Manihot esculenta Crantz) sobre o desempenho de cordeiros e sua ingestão de Cianeto de hidrogênio. Ciência do gado, v.131, n.2, p.155-161, 2010.

IBGE. Mandioca. Levantamento Sistemático da Produção Agrícola. Disponível em:<https://sidra.ibge.gov.br/tabela/6588>. Acesso em: jul. 2019.

LIMA, A.M. Podridão Radicular da Mandioca Causada por Phytopythium sp.: Metodologias de Inoculação e Prospecção de Genes de Resposta. (Tese de doutorado em agronomia). Universidade Federal Rural da Amazônia - UFRA. p.131, 2017.

MATSUI, K.N.; LAROTONDA, F.D.S.; LUIZ, D.B.; PIRES, A.T.N.; LAURINDO, J.B. Utilização do Resíduo de Mandioca na Produção de Bandejas Descartáveis. Revista CERES, v. 50, n. 292, 2003.

MATTOS, P.L.P.; BEZERRA, V.S. 2003. Cultivo da Mandioca para o Estado do Amapá. Embrapa Mandioca e Fruticultura. Sistemas de Produção 2. Disponível em:< https://sistemasdeproducao.cnptia.embrapa.br/FontesHTML/Mandioca/mandioca_amapa/adu bacao.htm>. Acesso em: jul. 2019.

MODESTO JÚNIOR, M.S.; ALVES, R.N.B. Cultura da Mandioca. Embrapa, Brasília-DF, 2016, p.36.

NORMANHA, E.S.; PEREIRA, A.S. Aspectos Agronômicos da Cultura da Mandioca (Manihot utilíssima Pohl). BRAGANTIA, Boletim Técnico da Divisão de Experimentação e Pesquisa, Campinas. v.10, n.7, 1950.

PACHÊCO, N. A.; BASTOS, T. X.; CREÃO, L. G. C. Boletim agrometeorológico de 2008 para Tomé-Açu, PA. Belém, PA: Embrapa Amazônia Oriental, p. 36, 2009 (Documentos, 361). 
RÓS, A.B.; SÃO JOÃO, R.E. Desempenho agronômico e uso eficiente da terra em arranjos de plantas de mandioca e batata-doce. Rev. Ceres, Viçosa, v. 63, n.4, p. 517-522, 2016.

SANTOS, R.T.S.; SILVA, I.S.O; RIBEIRO, P.L.L.; SOUZA, C.O.; DRUZIAN, J.I.; RYBKA, A.C.P.; CASTRO, C.D.P.C.; BIASOTO, A.C.T. Estudo Prospectivo de Documentos de Patentes Relacionados aos Produtos e Subprodutos Alimenticios da Mandioca. Cad. Prospec., Salvador, v. 11, p.316-327, 2018.

SEAB - Secretaria de Estado da Agricultura e do Abastecimento (2016). DERAL Departamento de Economia Rural Mandioca. Análise da Conjuntura Agropecuária. Disponível em:<http://www.agricultura.pr.gov.br/arquivos/File/deral/Prognosticos/2017/Mandioca_2016 _17.pdf.> Acesso em: jul. 2019.

SIVIERO, A.; SCHOTT, B. Caracterização Botânica e Agronômica da Coleção de Mandioca da Embrapa Acre. Revista Raízes e Amidos Tropicais, v.7, p. 31-41, 2011.

VALENTE, M.A.; WATRIN, O.S.; CASTRO, A.R.C. Mapeamento Detalhado dos Solos da Fazenda Experimental da Embrapa Amazônia Oriental em Tomé-Açu, PA. Empresa Brasileira de Pesquisa Agropecuária Embrapa Amazônia Oriental. Ministério da Agricultura, Pecuária e Abastecimento, Belém-PA, p. 1-35, 2014 (Documentos, 405). 